\title{
FAMILY, SCHOOL AND NEIGHBORHOOD FACTORS MODERATING THE RELATIONSHIP BETWEEN PHYSICAL ACTIVITY AND SOME ASPECTS OF MENTAL HEALTH IN ADOLESCENTS
}

\author{
${ }^{1}$ Institute of Mother and Child Foundation, Warsaw, Poland \\ ${ }^{2}$ Institute of Mother and Child, Warsaw, Poland \\ Department of Child and Adolescent Health \\ ${ }^{3}$ Nofer Institute of Occupational Medicine, Łódź, Poland \\ Department of Work Physiology and Ergonomics
}

DOROTA KLESZCZEWSKA ${ }^{1}$, JOANNA MAZUR ${ }^{2}$, and JADWIGA SIEDLECKA ${ }^{3}$

\begin{abstract}
The impact of physical activity on mental health is widely described in literature. Less attention is given to factors which may modify this correlation, except for gender. The aim of this study was to conduct a qualitative assessment of such papers relating to children and young people. Selected papers were evaluated with regard to additional factors related to family, school and neighborhood. Attention was drawn to the definitions of these variables, the methods of analysis, and the content of the discussion. The starting point for this study included 7 systematic reviews published in 2006-2018. A total of 161 full articles described in detail in those reviews, and representing different research patterns, were selected for qualitative analysis. They met the criteria for the type of publication, mental health outcome, the direction of association, and the age group. A supplementary section of this paper contains a review of Polish literature from the Polish Medical Bibliography, and an analysis of national studies and some more recent papers not included in the analyzed reviews. It was demonstrated that 33 papers analyzed environmental variables to a greater degree than the characteristics of the sample. Twenty-three papers containing the results of statistical analyses were considered to be of particular interest. Almost $50 \%$ of these included both the socio-economic position of the family and the characteristics of the neighborhood. However, only 1 featured stratification of the sample with regard to contextual environmental variables. The obtained results are of great practical importance. Firstly, development of the research into environmental moderators should be advocated. Secondly, the social context in which adolescents grow up should be taken into account when designing intervention programs. Int J Occup Med Environ Health. 2019;32(4):423-39
\end{abstract}

Key words:

family, physical activity, environment, adolescents, mental health, neighborhood

\section{INTRODUCTION}

The impact of physical activity on adolescent health has been the subject of researchers' interest for years [1]. The majority of papers focus on general fitness and on reducing the risk of non-communicable diseases as a health effect. The current life course perspective focuses mostly on the prevention of obesity [2], cardiovascular problems [3], diabetes [4], and cancer [5].

Physical activity is often listed among the group of factors protecting adolescent mental health and enhancing the cognitive functions of young people [6,7]. While trying to explain the mechanisms behind that correlation, researchers

Received: October 1, 2018. Accepted: March 5, 2019.

Corresponding author: Dorota Kleszczewska, Institute of Mother and Child Foundation, Kasprzaka 17a, 01-211 Warsaw, Poland (e-mail: dorota.kleszczewska@imid.med.pl). 
often emphasize its 2-way character. In the literature review by Spruit et al., a range of attributes of physical activity were identified which might affect mental well-being [8]. Physical activity leads to the release of endorphins, increased blood flow, and enhanced brain oxygenation. The regulation of blood pressure and pulse may reduce stress, anxiety, and symptoms of depression. The circumstances of practicing sports also affect the development of social competences. Learning the rules of fair play, strengthening the ability to resolve conflicts, making decisions, and collaborating with others are worth mentioning. Attending sports classes can have a positive impact on tightening social bonds and contribute to shaping one's personality. Coaches play an important role in the lives of young people who practice sports; they become natural authority figures. Taking part in organized team sports classes can enable integration into a given environment. Sport may prevent the social exclusion of adolescents from poorer families and more deprived regions. Finally, it is assumed that physical activity strengthens self-concept; i.e., a positive view of oneself and one's abilities, owing to achieving the goals set in sports.

A separate strand of research relates to the social determinants of child and adolescent health. Numerous health problems intensify in less privileged groups. Affluence and positive social relations may prevent many health problems, in particular in the field of mental health. Two national reports on social inequalities in child and adolescent health in Poland have demonstrated that both physical activity and mental well-being depend on the family structure and affluence, and on the level of social capital deprivation in the region of residence $[9,10]$.

In light of the available knowledge, few papers consider the impact of socio-economic status (SES) on the association between physical activity and the mental health of children and adolescents, and the components of this relationship. From the statistical perspective, an investigation of such correlations means an assessment of the interaction between variables [11]. A hypothesis can be made that there are certain factors, connected with the family and the broad environment (both at school and in the region of residence), which moderate the impact of physical activity on mental well-being. Identifying such factors and describing the mechanisms of association might enable the design of programs adjusted to specific groups and different settings. The aim of this review was to verify the degree to which the authors of studies on the relationship between physical activity and the mental health of school-age adolescents considered additional factors related to family, school and neighborhood (FSN).

The following research questions were asked:

- How often are FSN factors listed?

- Which FSN factors are listed most frequently?

- Are specific results listed which describe the effects of FSN factors?

- Are the effects of interactions between FSN factors and physical activity, as predictors of mental health, analyzed?

- How often do the authors refer to the significance of FSN factors in the discussion and try to define the direction of further studies?

- The above questions aim to facilitate formulating conclusions about the limitations of the published studies' results and to indicate a direction for future analyses.

\section{METHODS}

The papers previously identified as prominent in the English-language literature reviews and meta-analyses were reviewed. This kind of an approach falls within the "review of reviews" strand. A supplementary element included in this paper is a review of Polish literature from the Polish Medical Bibliography (PBL) and an analysis of national studies owned or conducted by the authors of this paper. Similar attempts at synthesizing the knowledge of the impact of physical activity on mental health have been made previously, but not with regard to the occurrence of additional variables and the effects of interaction [12]. On the 
contrary, Welch et al. conducted a review of intervention studies with regard to SES, without focusing on the target group, the kind of intervention, and health outcomes [13]. An assumption was made that physical activity, or a lack of it, may affect mental health, excluding the reviews and studies of reverse relationships.

The selection of reviews was preceded by a systematic search of PubMed and the Cochrane Systematic Reviews Database. The authors searched PubMed for papers published in 2010-2018 with terms (in the title) relating to various indications of physical activity or a lack of it (e.g., physical activity, sport, exercises, sedentary classes), and referring to, in the title or the abstract, mental or psychosocial health outcomes (e.g., depression, anxiety, selfesteem, cognitive functioning, prosocial behavior). Mental health problems could be diagnosed or symptomatic. Reviews of papers referring only to externalized problems (e.g., aggression, delinquency, conduct, behavior), and to the use of psychoactive substances, were omitted. The reviews could include a description of intervention studies (randomized control trials [RCT], quasi-experimental, etc.) or analytical ones (cross-sectional, longitudinal). Limitations regarding the year of publication were omitted while searching through the Cochrane database.

Seven reviews published in the last 20 years were selected (Table 1), which related to various issues and different study designs. All of these, in part or in full, were related to school-age adolescents. The investigated groups came from the general population or included individuals subjected to therapy. The interventions were preventive or therapeutic in nature.

Two reviews focused on intervention studies, 3 were dominated by cross-sectional and longitudinal studies, while the other 2 featured mixed study designs.

Table 1. Source reviews on the relationship between physical activity and mental health, published in 2006-2018

\begin{tabular}{|c|c|c|c|c|c|}
\hline \multirow{2}{*}{ Reference } & \multirow{2}{*}{$\begin{array}{c}\text { Reviewed } \\
\text { publication time }\end{array}$} & \multirow{2}{*}{ Description } & \multirow{2}{*}{ Study type } & \multicolumn{2}{|c|}{ Papers } \\
\hline & & & & identified & selected \\
\hline Larun et al., 2006, USA [15] & $(1983-2005)$ & $\begin{array}{l}\text { exercise in prevention and treatment } \\
\text { of anxiety and depression }\end{array}$ & RCT & 3665 & 16 \\
\hline Tremplay et al., 2011, Canada [16] & $(1958-2010)$ & $\begin{array}{l}\text { the influence of sedentary behaviors } \\
\text { on self-esteem, prosocial behaviors } \\
\text { and cognitive functioning }\end{array}$ & $\begin{array}{l}\text { RCT, QE, } \\
\text { CS, L }\end{array}$ & 5291 & 232 \\
\hline Eime et al., 2013, UK [17] & $(1993-2011)$ & $\begin{array}{l}\text { the effect of sport participation } \\
\text { on psychosocial health }\end{array}$ & CS, L & 3668 & 30 \\
\hline Spruit et al., 2016, Netherlands [8] & $(1974-2015)$ & $\begin{array}{l}\text { the influence of sport or exercise } \\
\text { aerobic intervention on externalizing } \\
\text { and internalizing problems or academic } \\
\text { achievement }\end{array}$ & RCT, QE & 546 & 57 \\
\hline Hoare et al., 2016, Australia [18] & $(2002-2015)$ & sedentary behaviors and mental health & $\begin{array}{c}\text { CS, L, } \\
\text { RCT (one) }\end{array}$ & 551 & 32 \\
\hline Watson et al., 2017, Australia [19] & $(2007-2015)$ & $\begin{array}{l}\text { the impact of classroom-based physical } \\
\text { activity on cognitive function }\end{array}$ & $\begin{array}{l}\text { RCT, QE, } \\
\text { WS }\end{array}$ & 7246 & 39 \\
\hline Boberska et al., 2018, Poland [20] & $(2006-2016)$ & $\begin{array}{l}\text { sedentary behaviors and health-related } \\
\text { quality of life - a systematic review and } \\
\text { meta-analysis }\end{array}$ & RCT, CS, L & 743 & 8 \\
\hline
\end{tabular}

CS - cross-sectional studies; L - longitudinal studies; QE - quasi-experimental intervention studies; RCT - randomized controlled trials; WS - within subject study design. 


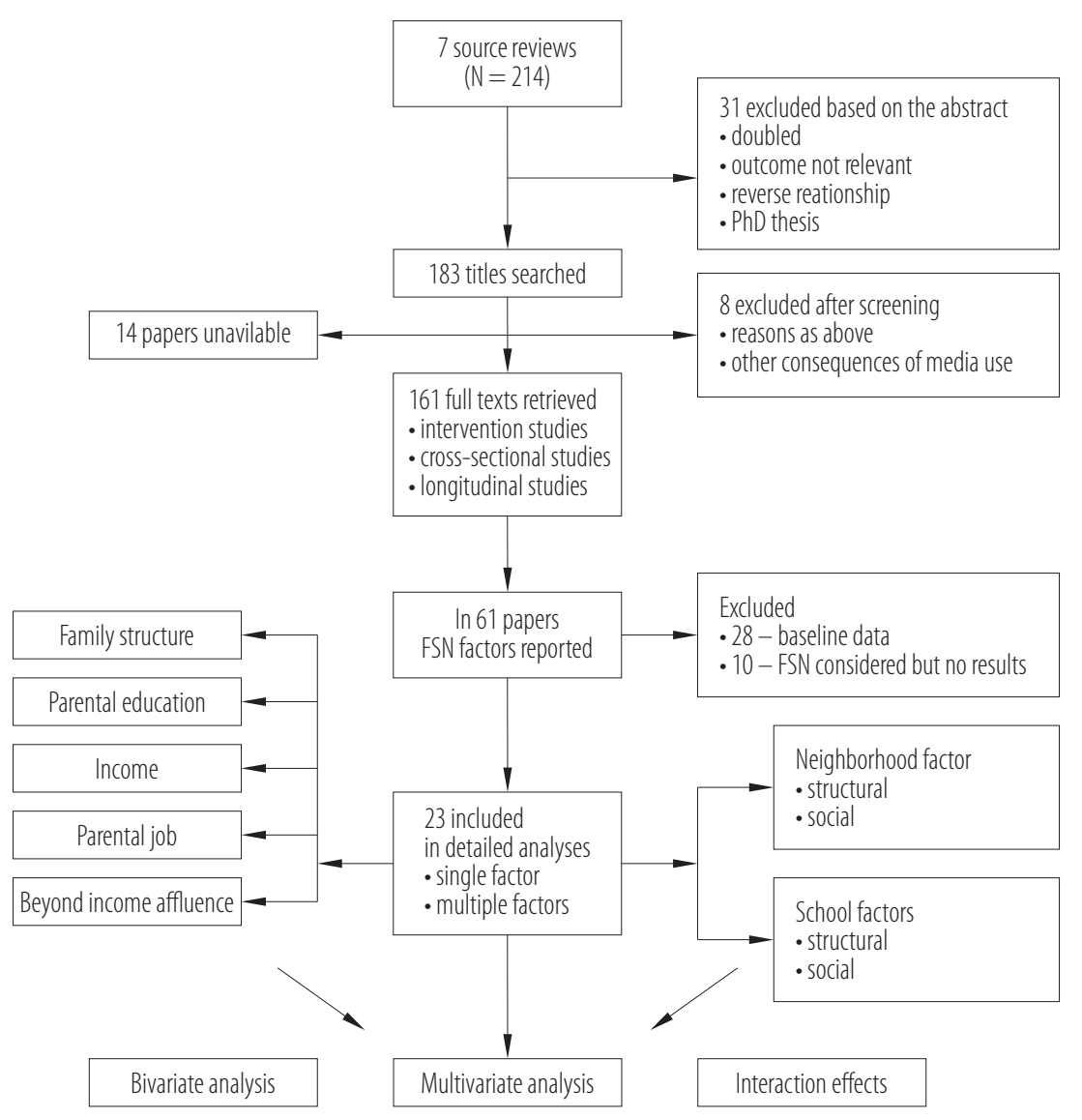

Figure 1. The strategy of selecting and analyzing the papers reviewed in the study on family, school and neighborhood (FSN) factors impact on physical activity and mental health correlation

Figure 1 shows the strategy for selecting and analyzing the papers, which is an adaptation of the PRISMA (Preferred Reporting Items for Systematic Reviews and Meta-Analyses) approach, recommended for systematic reviews. The PRISMA is an evidence-based minimum set of items aimed at helping the authors to report a wide array of systematic reviews and meta-analyses of health care interventions. The original PRISMA checklist includes 27 items pertaining to the content of a systematic review and metaanalysis, which include the title, abstract, methods, results, discussion and funding [14]. The schema employed in this study included a preliminary identification of papers, screening, eligibility assessment, as well as quantitative assessment and/or qualitative assessment of the papers which met the criteria adopted by the authors of the review.
It was decided that this review would feature a qualitative review of selected papers with regard to the methodology and the content of discussion.

The starting point included 214 papers in total, selected in 7 reviews. A total of 39 papers were eliminated from this group in 2 stages because they failed to meet the inclusion criteria previously identified; doctoral dissertations were also excluded. In the second attempt, after reading through the texts, it was concluded that some of the papers related to the psychosocial consequences of using the media; i.e., they did not include analyses of the time spent without moving. Access was gained to 161 full texts which met the required criteria. Their content was analyzed with regard to the occurrence of FSN factors potentially affecting the relationship between physical activity and mental health. 
Three ways of using these types of factors were identified; i.e., at the stage of selecting the target group and its characteristics, at the stage of analyses, but without listing the results relating to FSN variables, and at the stage of analyses, including listing specific results. The core part of this paper consists of analyzing the latter group.

\section{Classification of context variables}

While classifying the variables which may affect the association between physical activity and adolescent mental health, traditional divisions used in the analyses of social determinants of health were taken into account. The superior division included the family, school and neighborhood. As far as the family characteristics are concerned, the typical measurements of the social standing (income, education, employment) were supplemented with non-income measurements of the family affluence and structure. Information about employment may include the fact of being employed, the social class defined on the basis of the kind of work performed, or the prestige of the profession. As for features of the environment, the neighborhood and school environment were highlighted. Either of these could be assessed by structural factors related to physical conditions, as well as by social relations (neighborhood social capital, school climate).

\section{RESULTS}

\section{Description of source reviews}

The conclusions of the 7 selected literature reviews confirm the positive impact of physical activity on various aspects of the mental and psychosocial health of adolescents. It was verified whether or not the authors of the reviews referred in their syntheses to potential moderating factors.

The review by Larun et al. was relatively the most critical; it included the results of studies of RCT which are the highest in the hierarchy of epidemiological studies [15]. The collected data were described in 16 papers and re- lated to 1191 adolescents participating in various intervention programs containing a component of physical activity. The study was restricted to interventions which aimed to reduce anxiety and depression. It was determined that physical activity had a stronger protective effect among the general population than among young people in treatment. The authors of the review emphasized that the inference was limited by sample non-homogeneity, which affected group selection, intervention type, and measuring instruments. A reference to those moderating factors which are related to the intervention type and physical activity intensity is worth mentioning.

The second analyzed review by Trempley et al. [16] stands out due to the number of papers discussed and the diversity of health indicators. The subject matter of the paper was the assessment of the impact of sedentary activities (mostly watching TV) on a variety of health aspects, including mental health. From the point of view of this analysis, the 14 papers in which the only indicator, or one of several indicators, was self-esteem are of particular importance. Examples were given of papers indicating the dose-response effect; i.e., the more time young people spend in front of the TV, the lower their self-worth. Another important area of the analyses related to the correlation between limiting the time spent in front of the TV and pro-social behaviors of adolescents analyzed on the basis of 18 articles. It was shown that the adolescents who watched TV less frequently were emotionally more stable, sensitive, and capable of establishing relations with peers. An advantage of the review by Trempley et al. is the measurement of the quality of information included in source papers using the Downs and Black index.

The chronologically third review in terms of publication was the literature review by Eime et al. [17]. It stands out from the other reviews selected by the study authors because of its focus on the benefits of the participation of children and adolescents in sports. The health outcomes included higher self-esteem, development of social competence, and a re- 
duction in depressive symptoms. The kind of sports activities was considered to be a moderating factor. It was demonstrated that team sports showed a stronger protective effect in comparison with individual classes. The authors were aware that the presented results of cross-sectional and observation studies did not allow for causal inference. From the point of view of the aims of this paper, it is worth noting that Eime et al. [17] devoted plenty of attention to discussing context variables. They proposed the "Health through Sport" conceptual model, which identified 3 levels of correlations between physical activity and health. Firstly, the model was based on Bronfenbrenner's bioecological model of development; secondly, it took into account two dimensions of participation in sports (informal vs. organized and individual vs. team); thirdly, it indicated physical, psychological, and social determinants.

The fourth of the selected reviews by Spruit et al. related solely to intervention studies [8]. The impact of various forms of physical activity on internalization problems, self-concept, and academic achievement was analyzed, confirming a correlation. The study design moderated the strength of the effect of physical activity interventions on internalizing problems. Studies using an RCT design showed weaker effects than studies using a quasi-experimental design. Inference was weaker in randomized studies than in other, less rigorous, study designs.

The results of the interventions carried out in community and clinical samples were also compared. An advantage of this review is the analysis of errors in inference resulting from the tendency to not publish the results of studies which are inconvenient for the authors; i.e., those where no significant correlations are found. The Spruit et al.'s study [8] has some limitations that need to be mentioned. Many studies had small samples and did not always provide enough information to code all the moderators. As a result, there might be a power problem in identifying moderators with a small or moderate influence. As with Larun et al., the moderating factors resulting from the characteristics of the intervention, and belonging to ethnic groups, were discussed in detail [15].

The fifth review by Hoare et al. analyzed mostly studies based on non-experimental patterns, including several longitudinal studies which provided stronger inference than cross-sectional ones [18]. An analysis was carried out of the impact of sedentary activities, with mostly negative measurements adopted as health outcomes, such as depression symptoms, anxiety episodes, suicidal thoughts, loneliness, and stress. In comparison with the previously discussed Tremplay et al.' review [16], using computers and playing computer games was more frequently discussed among sedentary activities [17]. An advantage of this review is a qualitative assessment of the selected papers with regard to methodology. Out of 32 analyzed papers, 12 were evaluated as good, 17 as average, while 3 were considered to be very poor. The main reservations included a lack of data on the validation of the tools used, the methods of random selection, and the indicators of the response rate (including the participation and retention rate). The paper by Hoare et al. stands out because of its strong emphasis on the practical aspects of the results with regard to public health measures [18].

The 2017 literature review by Watson et al. was more concerned than the 2 previous ones with the functioning in the role of a student [19]. The authors consider it as important since it relates to the school environment and interventions carried out at schools. The relationship was investigated between interventions based on physical activity outside physical education (PE) classes at school, or in its vicinity. The so-called classroom-based physical activity included short physical exercises during breaks between lessons and during lessons. A total of 39 interventions were described, which were assessed with regard to methodology. Only 3 papers were assessed as strong. The list of reservations regarding the poorer papers included no analysis of confounding factors.

The last of the selected reviews is the most recent - a review by a team from Poland published in 2018. It is in- 
teresting because of its mention of health-related quality of life, which was only sporadically discussed in previous outcome reviews. The impact of sedentary activities on the physical, mental, and social dimensions of the quality of life was discussed. Boberska et al., having analyzed 743 papers, selected only 27 publications for further examination [20]. The authors of this study decided to include only 8 articles about children and adolescents in their qualitative review. An advantage of this paper is that it draws attention to the objectivization of measuring physical activity as a moderating factor, comparing the results obtained among children and adults, as well as healthy and chronically ill populations.

\section{Synthetic description of the obtained results}

While analyzing the content of 161 articles, it was found that only in 61 of these $(37 \%)$ the authors made reference to the variables relating to the socio-economic status of the families of the children and adolescents, and to the features of their living environment or school. Moreover, in 28 out of 61 studies, this was limited only to an attempt to describe the sample with regard to these features. In the other 33 studies, the features of the family, school and neighborhood were taken into account as variables modifying the investigated correlations among physical activity, sedentary activities, various aspects of mental health, and general well-being. These kinds of analyses are usually accompanied by detailed characteristics of the sample. The precision of the description of the results turns out to vary. In 10 papers, multidimensional models (or mean values) are described, modified by the FSN variables, without listing the results relating to their significance. Those papers feature only a relevant note in the research methodology description or a footnote under Table 2.

Table 2 includes the characteristics of 23 prominent articles in which the impact of environmental variables is precisely analyzed. Examples were chosen of articles which are particularly interesting in terms of the selection of those variables and the methods of analysis, and which also show a different approach to potential analyses of interactions among predictors of selected mental health issues.

Firstly, in accordance with the research questions set at the beginning, it is worth summing up the information about contextual variables in use. These were greatly dependent upon the specificity of a given country, which also affected the terminology. Social classes were defined only in some countries [30,35] and parental education was a commonly used proxy measure. Likewise, complex indices of deprivation in administrative regions were used in some countries [22,32,41].

Family features are described in almost all the papers (20 out of 23 ). In 10 cases, $\geq 2$ family features are analyzed. Three papers are worth mentioning in which family characteristics are particularly comprehensive [28,36,37]. The authors made an assumption in this paper to exclude from the analyses demographic features and descriptions of cultural diversity; i.e., variables such as gender, age, race, ethnic group, or country of origin. The papers which stood out were those in which major emphasis was put on a more precise analysis of immigrant groups [31].

The features of the region are analyzed in 14 out of 23 articles; these are included in Table 2. The majority of these papers (11 of 14) analyze features of the environment in parallel with features of the family. Attempts are made to combine family and neighborhood characteristics into one construct [22]. Two papers deserve a mention; in these, the description of the environment is particularly extensive, including an assessment of the security level, social capital, and availability of sports infrastructure [22,26]. School features are analyzed in 7 papers, which usually consists of identifying the public-school status. Attempts are also made to define the SES of a school; for example, through the percentage of students benefiting from free meals [39]. Apart from family, neighborhood and school features, other contextual variables are considered to modify the relationship under study. Often, these include BMI, health 


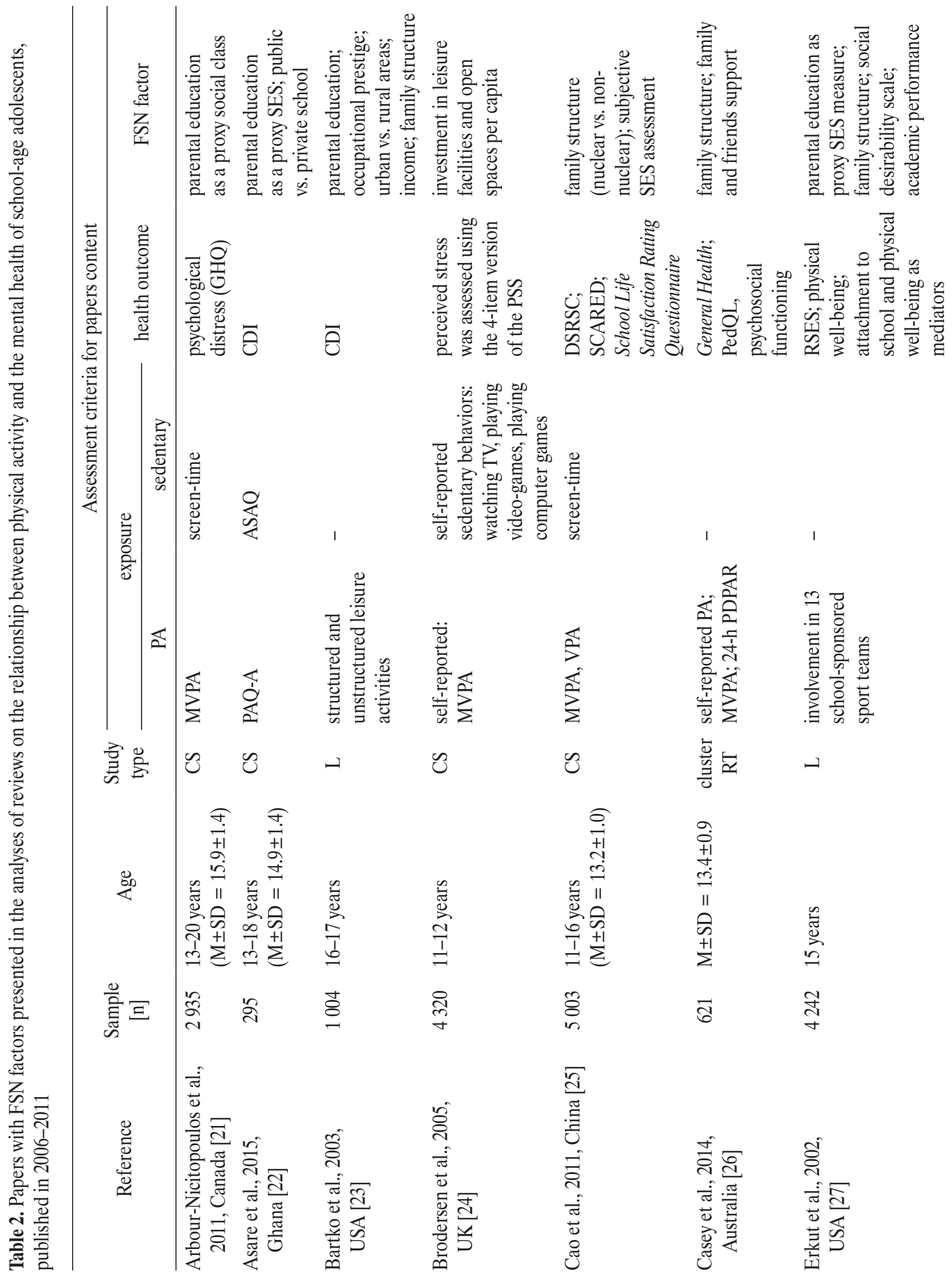



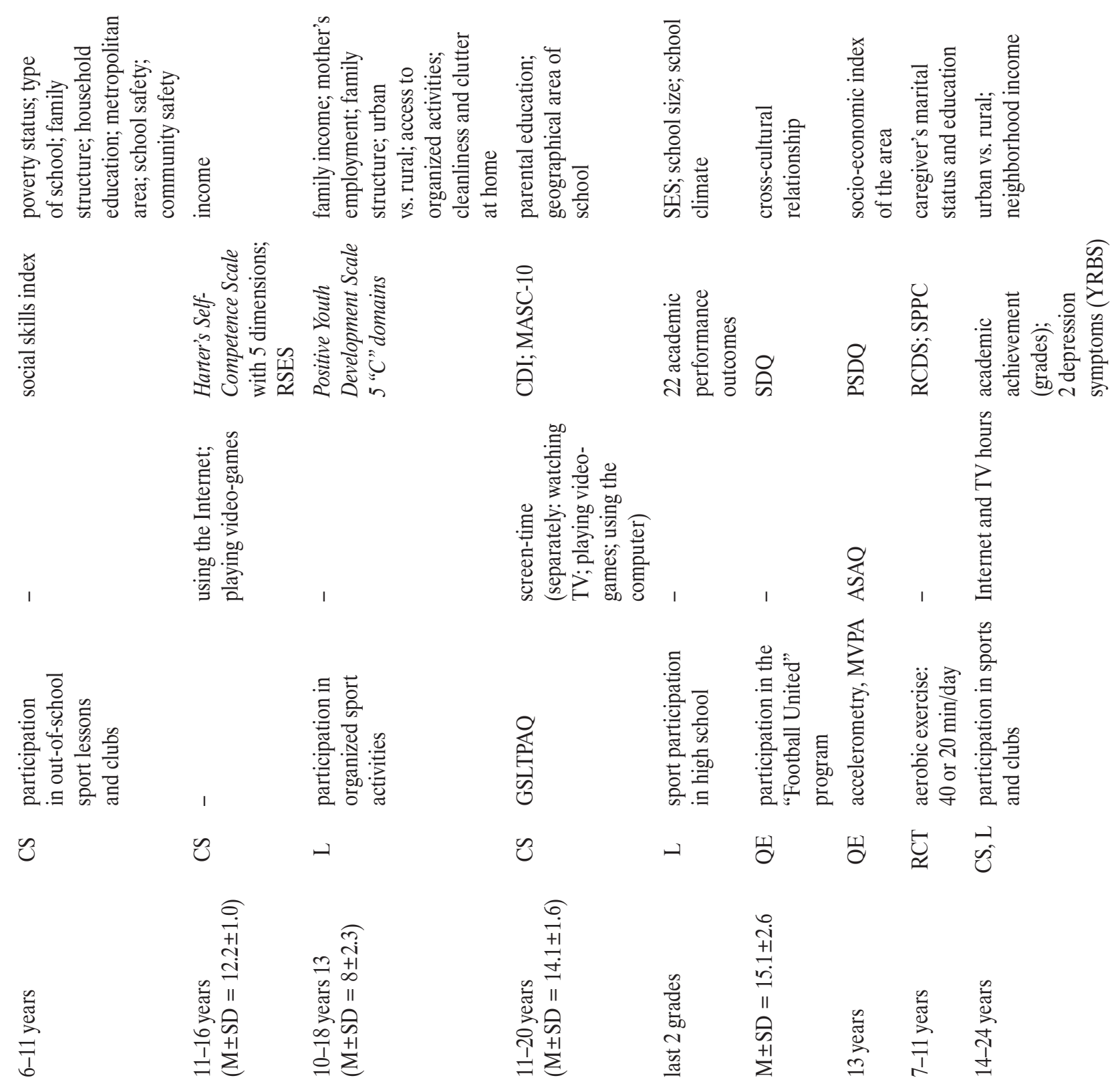

?

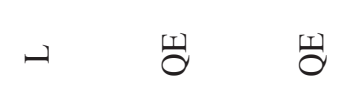

छ ज्ञ

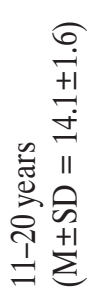

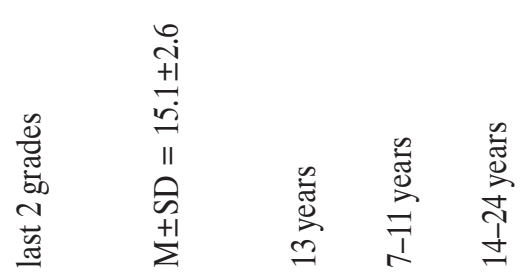

ำ

8

$\underset{\Xi}{-}$

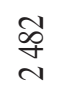

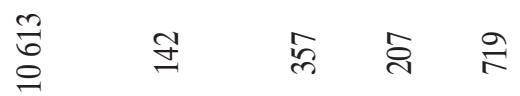

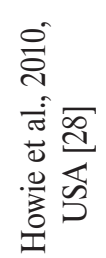

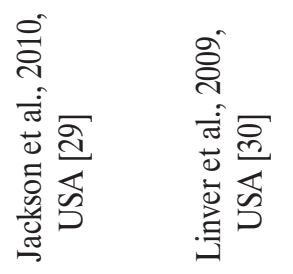

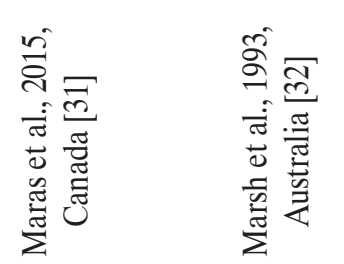

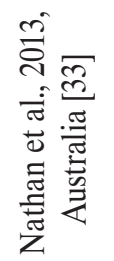

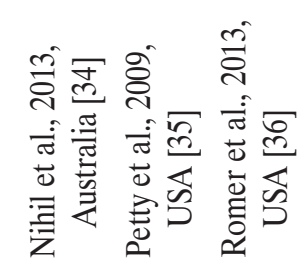




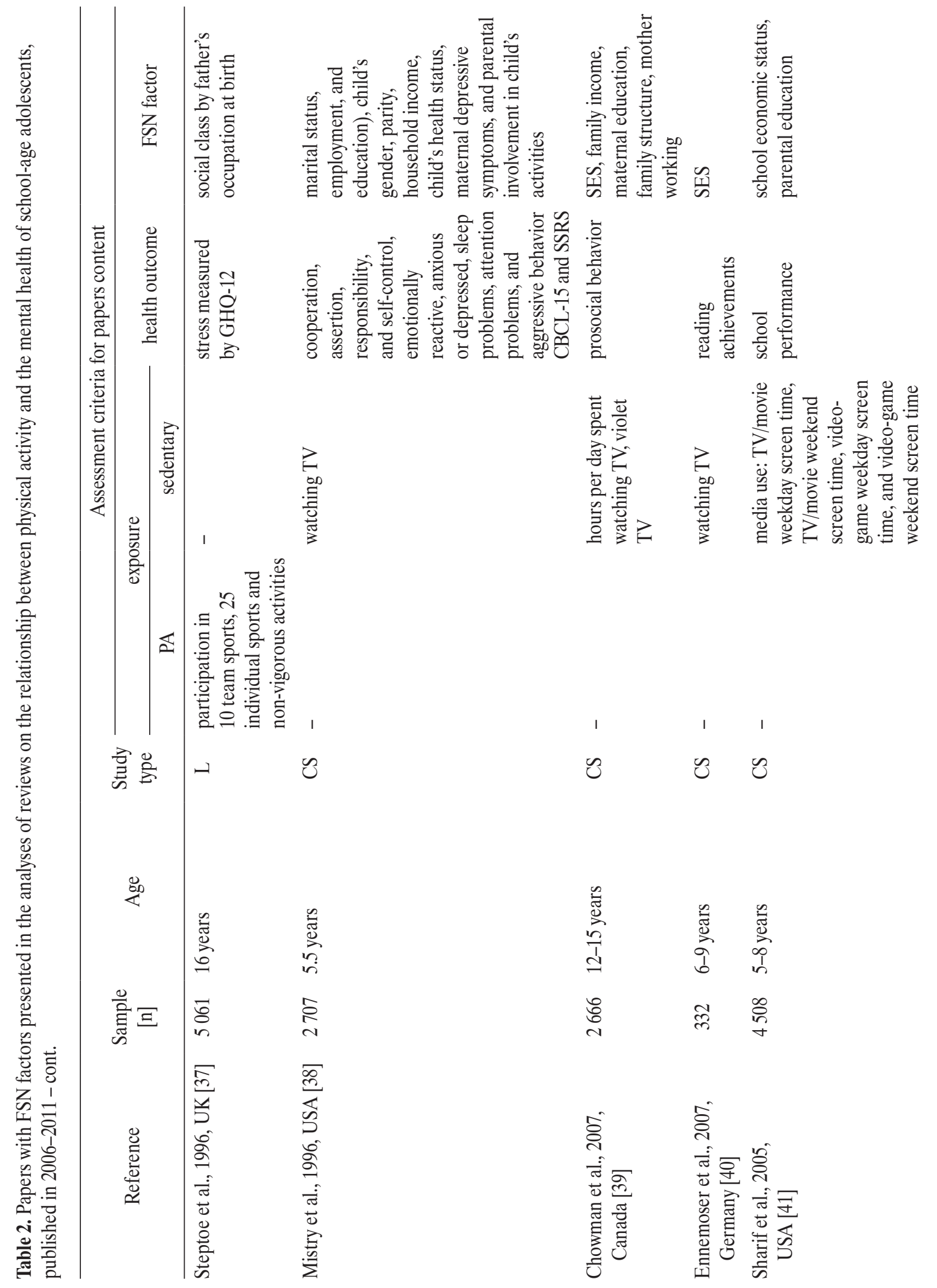




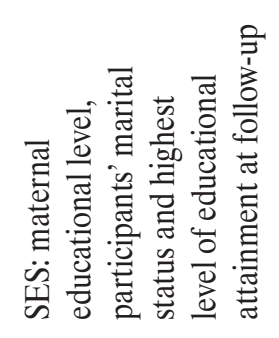

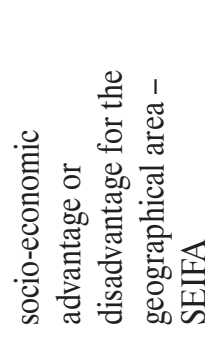

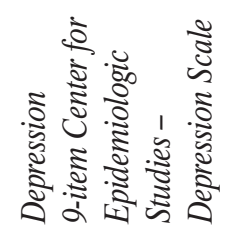

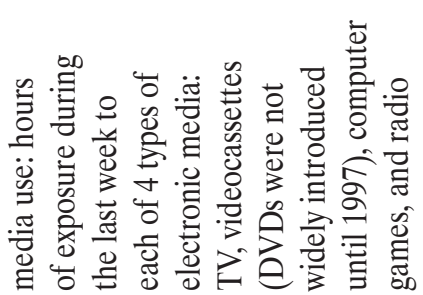

जि

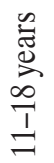

竎

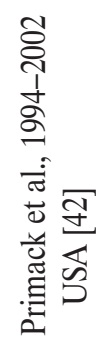

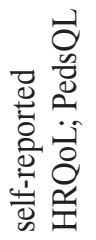
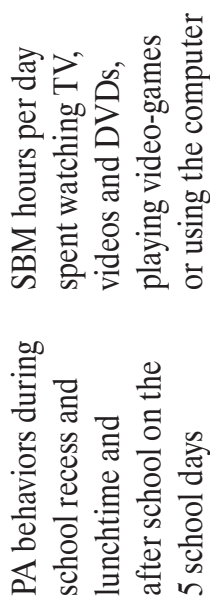

3

壳

$\underset{c}{?}$

๕ั่

宅呇

กิ

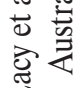

ฐ ॠ

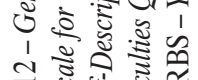

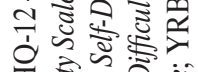

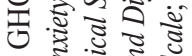

व

霡

芯芯芯芯

施弯

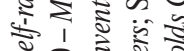

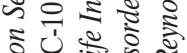

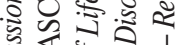

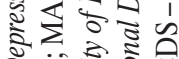

จ

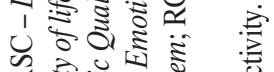

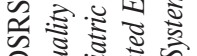

ค. 츄

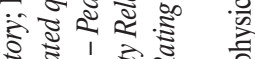

เป็

है

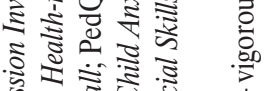

द्य

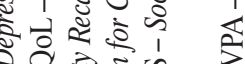

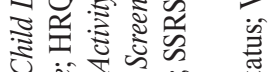

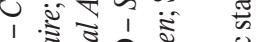

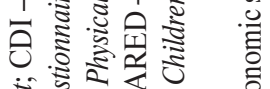

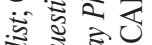

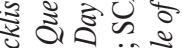

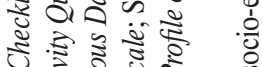

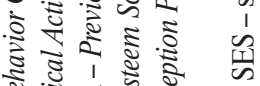

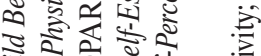

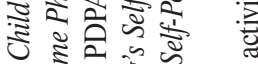

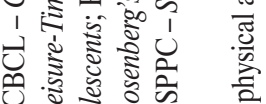

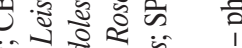

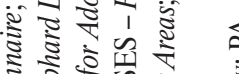

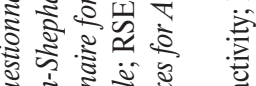

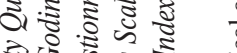

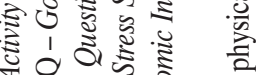

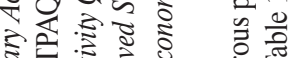

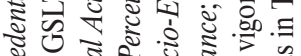

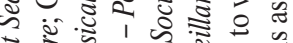

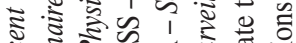

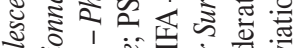

क्ष

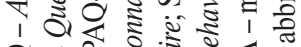

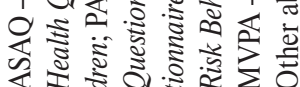


conditions, pubertal timing, and even climate conditions [39]. On the contrary, school achievements are featured in some papers as factors which modify the investigated correlations, while in others they are considered to be the main outcome of a measure of cognitive abilities.

Secondly, selected articles were examined with regard to the methods of analyses. In the greater majority (10/23), environmental variables occur as independent predictors in the presented models, which allows for an assessment of their impact on child and adolescent mental health. Other 8 papers compare adjusted and unadjusted models, which only allows for an assessment of the degree to which additional factors modify the correlation between physical activity and mental health. Other works present other analytical approaches, such as cluster analysis [21,28,34] or structural models [38].

Thirdly, a review of 23 selected papers was conducted with regard to the stratification of analyses due to additional factors. Only 3 papers stood out $[27,33,36]$. In the first one, the models of mental health conditioning are stratified according to the level of neighborhood deprivation (in 4 quartiles). In the second one, the stratifying factor is the level of risk of school failures, while in the third one the stratifying factor is ethnic background.

A review of the papers included in Table 3 indicates examples worth quoting, where the interaction effect is analyzed but without environmental variables. The focus of interest of some researchers is the interaction between physical activity and sedentary activities as predictors of mental health $[23,41]$ or attendance at organized and unorganized classes [26].

An analysis of the papers whose authors took into account the impact of FSN factors on the relationship between physical activity and adolescent mental health also shows diversity at the discussion level. Only some authors (11 out of 23) undertook to interpret the obtained results in the context of moderating factors. In 2 papers, the authors discussed the impact of low income on the self-worth of the investigated adolescents, and emphasized greater stress experienced by adolescents from families with a lower SES [27,35]. In the discussions, the correlations between low SES and the intensity of sedentary activities is also described. Adolescents from less affluent families spend significantly more time in front of the TV [21,38] but, on the other hand, more affluent adolescents enjoy greater access to multimedia entertainment, which may increase their exposure to violence [38].

Although ethnicity was not included in the FSN factors discussed in this review, it should be pointed out that the authors of 2 papers analyzed in detail the correlation between ethnic background and SES. They showed that adolescents from immigrant families more often attend schools of lower status and live in less affluent neighborhoods [42]. This background affects young people's attendance at sports classes and the impact of physical activity on the mental well-being of the investigated adolescents. It may also affect self-image, because dark-skinned adolescents tend to be less concerned with obesity and girls consider being overweight as an attribute of femininity [25]. Three authors listed insufficient analysis of FSN factors relating to upbringing or education, which can be moderators of the investigated correlation, as limitations of their studies $[21,32,42]$.

In some of the papers analyzed in this review, the authors include practical implications resulting from their research. They point to the need for developing public sports infrastructure in neighborhoods of lower economic status as well as providing support for less affluent families through dedicated scholarships $[24,37]$. They draw attention to using attendance in sport intervention programs as a factor which could integrate young people from diverse backgrounds [31]. The need to focus on individual groups and group-specific mental health problems is indicated. One paper proposes taking into account the features of neighborhood and upbringing in subsequent studies, and implementing intervention programs [32]. 


\section{Polish research}

To the best of the authors' knowledge, there are no extensive reviews of papers relating to the relationship of physical activity with the health of children and adolescents in the Polish literature. In the national bibliography, there are 156 papers related to this topic; these are mainly doctoral dissertations. These papers are mostly based on clinical data and related to adults. Only 23 papers concern adolescents. Two unpublished doctoral dissertations were identified; these analyze the relationship between physical activity and adolescents' well-being.

Attempts to evaluate the impact of environmental factors on the correlation between adolescents' physical activity and the subjective assessment of their self-related health have been undertaken in several Polish papers available to the authors of this study from their own resources. Because of the language, year and place of publication (chapters in hard-to-access books), these have not received international reviews. An advantage of these papers is their use of representative samples of large sizes and standardized tools, mostly based on the Health Behaviour in School-Aged Children (HBSC) survey research methodology.

Kołoło [46] conducted a multivariate analysis of the determinants of self-rated health (SRH) of school-aged adolescents aged 11-15, using the results of the Polish edition of the HBSC survey from $2010(\mathrm{~N}=4751)$. She determined that fulfilling the criteria for the level of moderate-to-vigorous physical activity increased the chances of good selfrating of health, after adjustment for gender, age, family affluence assessment and neighborhood characteristics. The independent predictors of SRH included family affluence and the level of deprivation, and social capital in the neighborhood. Moreover, among physically active adolescents, the protective effect of social capital was found to be stronger.

Dzielska and Nałęcz [47], using the results of the same edition of the HBSC survey, investigated the health-related quality of life among 15-year-olds ( $\mathrm{N}=1650)$, depending on vigorous or moderate physical activity. The mean level of the Kidscreen-10 index was assessed, which is considered in the literature as a measurement of general wellbeing. After adjustment for gender and physical activity, an important predictor of the quality of life was neighborhood, with rural areas turning out to be more beneficial. Moreover, while examining the Polish literature, the results of regional studies were identified, which are related to the topic of this paper. Those analyses usually concerned the level of physical activity among young people from a given school, town or municipality. The authors of those papers took into account the barriers to accessing sports infrastructure [48] and the costs related to undertaking physical activity [49].

The most recent paper taken from the authors' own resources was also dedicated to the assessment of the impact of environmental factors on the association between physical activity and adolescent well-being, which is an implementation of conclusions resulting from literature reviews [50]. It made use of the results of a survey of junior secondary school students conducted in $2015(\mathrm{~N}=4085)$. The originality of the paper also consists in an analysis of indirect effects and stratified analyses according to family affluence. As was demonstrated earlier, the papers highlighted in the reviews included such stratification only sporadically. It was demonstrated in the Polish authors' paper that vigorous physical activity was conducive to increased self-esteem, which in turn translated into improved general life satisfaction. The relationship between physical activity and self-esteem turned out to be much stronger in less affluent families.

\section{CONCLUSIONS}

The strengths of this review lie in the selection of highquality material from 7 literature review sources $[8,15-$ 20]. A preliminary selection had been made by the authors of those reviews - authorities in the field assess- 
ing the impact of physical activity on adolescent mental health, who may be considered independent experts. The authors of this study hope that the number of analyzed texts and the aforementioned strategy of material selection mitigate the limitations resulting from the difficulties in identifying and accessing all the texts belonging to this strand of research. The limitations of this study also include the delay resulting from the time elapsed between the research and the publication of its results, and between the publication and its secondary inclusion in the review. It may be assumed that methods of investigating complex interactions are being popularized and this kind of analysis can be found more often in the most recent papers.

By re-examining the papers selected by other researchers, the authors narrowed down their investigation to assessing the impact of environmental factors on the association between physical activity and some aspects of adolescent mental health. To the best of their knowledge, this is the first review with a qualitative analysis of the content and methodology of articles on the same subject. This study verified how often and in what way the analyses are adjusted for the additional impact of the selected features of family, school and neighborhood.

Firstly, it was found that in almost two-thirds of the papers there were no references to the socio-economic characteristics of the family and neighborhood, except for a brief description of the investigated groups. Secondly, many papers were limited to the information that the analyses were corrective; however, these did not quote any specific results. Thirdly, the more methodologically developed papers usually analyzed the impact of additional FSN variables by comparing the models of adjusted and unadjusted regression.

Only a few papers showed the association between physical activity and adolescent mental health in social groups distinguished by family affluence or neighborhood affluence. In literature, such analyses refer significantly more often to demographic factors (gender, ethnic group), which were omitted in this review. It seems reasonable to suggest drawing attention to the environment as a factor which moderates these kinds of correlations. The authors of the source reviews often raised the issue of moderating factors, but mostly with regard to the kind of physical activity, its intensity, and the precision of its measurement or the type of intervention.

Similar conclusions about too-rare inclusion of a broader social context of research were reached by Welch et al. [13]. Based on the already cited review of 224 intervention studies, they concluded that the most often quoted factor was the socio-economic description of the group included in the intervention. Only $12 \%$ of the analyzed papers included the results of comparative analyses of social groups, and $21 \%$ contained practical implications. This paper is limited to children and adolescents, as well as to 1 type of association, but it also comprises non-experimental studies. These have a low value of power to prove causation, but their advantages include large, often multi-thousand, samples. As a result, it is possible to estimate complex models of relationship, delving deeper into the mechanisms of investigated correlations.

On a positive note, there has been a growing interest in features of the environment as moderators of the correlation between physical activity and adolescent mental wellbeing. The neighborhood aspect should appear more often in papers on social inequalities in health, supplementing the impact of family social standing. In many countries, standards for measuring and assessing the impact of the environment are being created [51]. Taking into account the specificity of the environment is particularly important with regard to physical activity, which requires relevant infrastructure.

The obtained results should be reflected in the objectives of programs promoting physical activity among children and adolescents and, as a consequence, supporting their 
mental health. Family, school, neighborhood and other elements of the environment in which young people grow up may create barriers to accessing sports, but also provide support for adolescents to undertake physical activity.

\section{REFERENCES}

1. Rhodes RE, Janssen I, Bredin SSD, Warburton DER, Bauman A. Physical activity: Health impact, prevalence, correlates and interventions. Psychol Health. 2017;32(8):1-34, https://doi.org/10.1080/08870446.2017.1325486.

2. Classen T, Hokayem C. Childhood Influences on Youth Obesity. Econ Hum Biol. 2005;3(2):165-87.

3. Ahmad T, Testani MJ. Physical Activity Prevents Obesity and Heart Failure. Eur J Heart Fail. 2017;5(5):385-7, https://doi. org/10.1016/j.jchf.2017.03.006.

4. Sigal JR, Armstrong MJ, Bacon S, Boule N, Dasgupta K, Kenny GP, et al. Physical Activity and Diabetes. Can J Diabetes. 2018;42:54-63, https://doi.org/10.1016/j.jcjd.2017.10.008.

5. Kohler L, Garcia D, Robin B, Oren E, Roe DJ, Jacobs ET. Adherence to Diet and Physical Activity Cancer Prevention Guidelines and Cancer Outcomes: A Systematic Review. Cancer Epidemiol Biomarkers Prev. 2016;25(7):1018-28, https://doi.org/10.1158/1055-9965.EPI-16-0121.

6. Michaud PA, Jeannin A, Suris J. Correlates of extracurricular sport participation among Swiss adolescents. Eur J Pediatr. 2006;165(8):546-55, https://doi.org/10.1007/s00431-0060129-9.

7. Kanton W, Richardson L, Russo J, McCarthy CA, Rockhill C, McCauley E. Depressive symptoms in adolescence: The association with multiple health risk behaviors. Gen Hosp Psychiatry. 2010;32(3):233-9, https://doi.org/10.1016/j.genhosppsych.2010.01.008.

8. Spruit A, Assink M, van Vugt E, van der Put C, Stams GJ. The effects of physical activity interventions on psychosocial outcomes in adolescents: A meta-analytic review. Clin Psychol Rev. 2016;(45):56-71, https://doi.org/10.1016/j.cpr.2016. 03.006.
9. Wojtyniak B, Mazur J. [Social inequalities in the health of children and adolescents in Poland in the light of population studies]. Warsaw: NIZP-PZH; 2016. Polish.

10. Mazur J, Małkowska-Szkutnik A, editors. [School-aged children health in 2018 according to a new HBSC research model]. Warsaw: Institute of Mother and Child; 2018. Polish.

11. Hayes AF. Introduction to mediation, moderation and conditional process analysis. A regression-based approach. London: The Guilford Press; 2013.

12. Biddle SJ, Asare M. Physical activity and mental health in children and adolescents: a review of reviews. Br J Sports Med. 2011;45(11):886-95, https://doi.org/10.1136/bjsports-2011090185.

13. Welch V, Petticrew M, Ueffing E, Benkhalti Jandu M, Brand K, Dhaliwal B, et al. Does consideration and assessment of effects on health equity affect the conclusions of systematic reviews? A Methodology Study. PLoS ONE. 2012;7(3):31360, https://doi.org/10.1371/journal.pone.003 1360.

14. Moher D, Liberati A, Tetzlaff J, Altman DG. Preferred reporting items for systematic reviews and meta-analyses: the PRISMA statement. Ann Intern Med. 2009;151(4):264-9.

15. Larun L, Nordheim LV, Ekeland E, Hagen KB, Heian F. Exercise in prevention and treatment of anxiety and depression among children and young people. Cochrane Database Syst Rev. 2006;(3):CD004691, https://doi.org/10.1002/14651858. CD004691.pub2.

16. Tremblay M, LeBlanc AG, Kho ME, Saunders TJ, Larouche R, Colley RC, et al. Systematic review of sedentary behaviour and health indicators in school-aged children and youth. Int J Behav Nutr Phys Act. 2011;8:98, http://www.ijbnpa.org/content/8/1/98.

17. Eime RM, Young JA, Harvey JT, Charity M, Payne WR. A systematic review of the psychological and social benefits of participation in sport for children and adolescents: informing development of a conceptual model of health through sport. Int J Behav Nutr Phys Act. 2013;10:98, http:// www.ijbnpa.org/content/10/1/98. 
18. Hoare E, Milton K, Foster C, Allender S. The associations between sedentary behaviour and mental health among adolescents: a systematic review. Int J Behav Nutr Phys Act. 2016;13:108, https://doi.org/10.1186/s12966-016-0432-4.

19. Watson A, Timperio A, Brown H, Best K, Hesketh KD. Effect of classroom-based physical activity interventions on academic and physical activity outcomes: a systematic review and meta-analysis Int J Behav Nutr Phys Act. 2017;14:114, https://doi.org/10.1186/s12966-017-0569-9.

20. Boberska M, Szczuka Z, Kruk M, Knoll N, Keller J, Hohl D, et al. Sedentary behaviours and health-related quality of life. A systematic review and meta-analysis. Health Psychol Rev. 2018;12(2):195-210, https://doi.org/10.1080/17 437199.2017.1396191.

21. Arbour-Nicitopoulos KP, Faulkner GE, Hyacinth M, Irving MA. Multiple Health-Risk Behaviour and Psychological Distress in Adolescence. J Can Acad Child Adolesc Psychiatry. 2012;21(3):171-8.

22. Asare M, Danquah S. The relationship between physical activity, sedentary behaviour and mental health in Ghanaian adolescents. Child Adolesc Psychiatry Ment Health. 2015;9:11, https://doi.org/10.1186/s13034-015-0043-x.

23. Bartko TW, Eccles JS. Adolescent Participation in Structured and Unstructured Activities: A Person-Oriented Analysis. J Youth Adolesc. 2003;32(4):233-41.

24. Brodersen NH, Steptoe A, Williamson S, Wardle J. Sociodemographic, Developmental, Environmental, and Psychological Correlates of Physical Activity and Sedentary Behavior at Age 11 to 12. Ann Behav Med. 2005;29(1):2-11.

25. Cao H, Qian Q, Weng T, Yuan C, Sun Y, Wang H, et al. Screen time, physical activity and mental health among urban adolescents in China. J Prev Med. 2011;53:316-20.

26. Casey M, Harvey J, Telford A, Eime RM, Mooney A, Payne WR. Effectiveness of a school-community linked program on physical activity levels and health-related quality of life for adolescent girls. BMC Public Health. 2014;14:649.

27. Erkut S, Tracy A. Predicting Adolescent Self-Esteem from Participation in School Sports Among Latino Subgroups.
Hisp J Behav Sci. 2002;24(4):409-29, https://doi.org/10.1177/ 0739986302238212.

28. Howie EK, Schatz J, Pate RR. Acute Effects of Classroom Exercise Breaks on Executive Function and Math Performance: A Dose-Response Study. Res Q Exerc Sport. 2015;86(3):1-8, https://doi.org/10.1080/02701367.2015.1039 892.

29. Jackson LA, von Eye A, Fitzgerald HE, Zhao Y, Witt EA. Self-concept, self-esteem, gender, race and information technology. Comput Human Behav. 2010;26:323-8.

30. Linver MR, Roth JL, Brooks-Gunn J. Patterns of Adolescents' Participation in Organized Activities: Are Sports Best When Combined With Other Activities? Dev Psychol. 2009;45(2):354-67.

31. Maras D, Flament MF, Murray M, Buchholz A, Henderson KA. Screen time is associated with depression and anxiety in Canadian youth. J Prev Med. 2015;73:133-8.

32. Marsh HW, Peart ND. Competitive and Cooperative Physical Fitness Training Programs for Girls: Effects on Physical Fitness and Multidimensional. Self-Concepts. J Sport Exerc Psychol. 1988;10:390-407.

33. Nathan S, Kemp L, Bunde-Birouste A, MacKenzie J, Evers C, Shwe TA. We wouldn't made friends if we didn't come to Football United: the impacts of a football program on young people's peer, prosocial and cross-cultural relationships. BMC Public Health. 2013;13:399.

34. Nihill G, Lubans D, Plotnikoff R. Associations between sedentary behavior and self-esteem in adolescent girls from schools in low-income communities. Ment Health Phys Act. 2013;6:30-5.

35. Petty KH, Davis CL, Tkacz J, Young-Hyman D, Waller JL. Exercise Effects on Depressive Symptoms and Self-Worth in Overweight Children: A Randomized Controlled Trial. J Pediatr Psychol. 2009;34(9):929-39, https://doi.org/10.1093/ jpepsy/jsp007.

36. Romer D, Bagdasarov Z, More E. Older Versus Newer Media and the Well-being of United States Youth: Results. J Adolesc Health. 2013;52:613-9. 
37. Steptoe A, Butler N. Sports participation and emotional wellbeing in adolescents. Lancet. 1996;347(9018):1789-92.

38. Mistry KB, Minkovitz CS, Strobino DM, Borzekowski DLG. Children's Television Exposure and Behavioral and Social Outcomes at 5.5 Years: Does Timing of Exposure Matter? J Pediatr. 2007;120(1):762-9.

39. Chowman J, Stewart JM. Television and the behaviour of adolescents: Does socio-economic status moderate the link? Soc Sci Med. 2007;65(7):1324-36, https://doi.org/10.1016/ j.socscimed.2007.05.019.

40. Ennemoser M, Schneider W. Relations of television viewing and reading: Findings from a 4-year longitudinal study. J Educ Psychol. 2007;99(2):349-68, https://doi. org/10.1037/0022-0663.99.2.349.

41. Sharif I, Sargent JD. Association between television, movie, and video game exposure and school performance. J Pediatr. 2006;118(4):1061-70, https://doi.org/10.1542/peds.20052854.

42. Primack BA, Swanier B, Georgiopoulos AM, Land SR, Fine MJ. Association Between Media Use in Adolescence and Depression in Young Adulthood: A Longitudinal Study. Arch Gen Psychiatry. 2008;66(2):181-8, https://doi. org/10.1001/archgenpsychiatry.2008.532.

43. Lacy KE, Allender SE, Kremer PJ, de Silva-Sanigorski AM, Millar LM. Screen time and physical activity behaviours are associated with health-related quality of life in Australian adolescents. Qual Life Res. 2012;(21):1085-99, https://doi. org/10.1007/s11136-011-0014-5.

44. Bonhauser M, Fernandez G, Puschel K, Yanez F, Montero J, Thompson B, et al. Improving physical fitness and emotional well-being in adolescents of low socioeconomic status in
Chile: results of a school-based controlled trial. Health Promot Int. 2005;(2):113-22.

45. Galobardes B, Shaw M, Lawlor DA, Lynch JW, Davey Smith G. Indicators of socioeconomic position. J Epidemiol Community Health. 2006;60(2):95-101.

46. Kołoło $\mathrm{H}$. [The impact of physical activity on the selfassessed health of 11,13 and 15-year-olds according to the background of socio-economic conditions]. In: Mazur J, editor. [Social determinants of health of school-aged youth]. Warsaw: Instytut Matki i Dziecka; 2011. p. 93-110. Polish.

47. Dzielska A, Nałęcz H. [Physical activity of adolescents and quality of life related to health. Results of research in confrontation with the recommended level of physical activity]. In: Szymborski J, Zatoński W, editors. [Health of children and adolescents in the socio-medical dimension. Public Health - Monographs]. Warsaw: Wszechnica Polska; 2013. p. 32-50. Polish.

48. Kozłowska E, Kowalczyk A, Marzec A. Physical activity and some of its conditions among secondary-school youth. J Educ Health Sport. 2015;5(9):386-96.

49. Napierała M, Szark-Eckardt MA, Żukowska H, Kuska M, Zukow W. Physical activity a healthy lifestyle in junior high school in Bydgoszcz. J Health Sci. 2014;4(11):11-32.

50. Kleszczewska D, Dzielska A, Salonna F, Mazur J. The Association Between Physical Activity and General Life Satisfaction in Lower Secondary School Students: The Role of Individual and Family Factors. Community Ment Health J. 2018;54(8): 1245-52, https://doi.org/org/10.1007/s10597-018-0309-x.

51. Allik M, Brown D, Dundas R, Layland AH. Developing a new small-area measure of deprivation using 2001 and 2011 census data from Scotland. Health Place. 2016;39:122-30.

This work is available in Open Access model and licensed under a Creative Commons Attribution-NonCommercial 3.0 Poland License - http://creativecommons.org/ licenses/by-nc/3.0/pl/deed.en. 